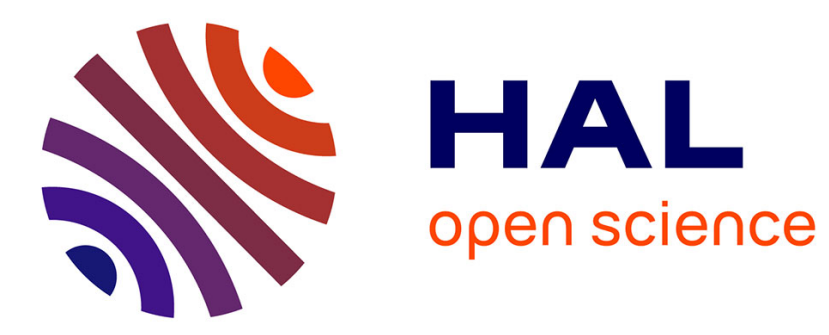

\title{
Weather Regimes in the Euro-Atlantic and Mediterranean sector and relationship with West African rainfall over the period 1989-2008 from a Self-Organizing Maps Approach
}

Irene Polo, Albin Ullmann, Pascal Roucou, B. Fontaine

\section{To cite this version:}

Irene Polo, Albin Ullmann, Pascal Roucou, B. Fontaine. Weather Regimes in the Euro-Atlantic and Mediterranean sector and relationship with West African rainfall over the period 1989-2008 from a Self-Organizing Maps Approach. Journal of Climate, 2011, 24 (13), pp. 3423-3432. hal-00557949

\section{HAL Id: hal-00557949 \\ https://hal.science/hal-00557949}

Submitted on 20 Jan 2011

HAL is a multi-disciplinary open access archive for the deposit and dissemination of scientific research documents, whether they are published or not. The documents may come from teaching and research institutions in France or abroad, or from public or private research centers.
L'archive ouverte pluridisciplinaire HAL, est destinée au dépôt et à la diffusion de documents scientifiques de niveau recherche, publiés ou non, émanant des établissements d'enseignement et de recherche français ou étrangers, des laboratoires publics ou privés. 


\title{
Weather Regimes in the Euro-Atlantic and Mediterranean sector and relationship with West African rainfall over the period 1989-2008 from a Self-Organizing Maps Approach
}

\author{
Irene Polo
}

Fisica de la Tierra, Astronomia y Astrofisica I, Universidad Complutense de Madrid, Madrid, Spain.

\begin{abstract}
Albin Ullmann
Centre de Recherches de Climatologie, CNRS-Université de Bourgogne, Dijon, France.

Pascal Roucou

Centre de Recherches de Climatologie, CNRS-Université de Bourgogne, Dijon, France.

Bernard Fontaine

Centre de Recherches de Climatologie, CNRS-Université de Bourgogne, Dijon, France.
\end{abstract}




\section{Abstract}

Weather Regimes (WR) have been defined over the Euro-Mediterranean region $\left[60^{\circ} \mathrm{W}-60^{\circ} \mathrm{E}\right.$; $\left.15^{\circ} \mathrm{N}-70^{\circ} \mathrm{N}\right]$ from May to October season using the daily Sea Level Pressure, $700 \mathrm{hPa}$ geopotential height and specific humidity from ERA-interim over 1989-2008 period. Computations are based on a neural network classification technique referred to as Self Organizing Maps and the WR produced can be used by the community for comparison with other periods, projection onto model outputs, seasonal prediction or teleconnection studies. The article particularly examines the relationship between WR and West African (WA) rainfall and our results suggest that changes in particular WR frequencies can account for part of WA interannual rainfall variability. Thus during anomalous wet (dry) years in WA, both higher frequencies of occurrence of WR related to negative (positive) summer NAO-like pattern and less frequent WR related to positive (negative) summer NAO-like pattern are attested in July and August (hereafter $\mathrm{SN}-$ and $\mathrm{SN}+$ ). This is associated with a zonal symmetric pattern, consistent along the middle troposphere, i.e. low pressure anomaly centered over $50^{\circ} \mathrm{N}-20^{\circ} \mathrm{W}$ and Eurasia (Greenland) and high pressure anomaly centered over Iceland (central Europe) for $\mathrm{SN}-(\mathrm{SN}+)$. Another striking characteristic of $\mathrm{SN}-(\mathrm{SN}+)$ is southeastward (southwestward) surface anomalous winds flowing from (to) the Atlantic Ocean at $20^{\circ} \mathrm{N}$ and therefore able to enhance (weaken) wet convection. That sea surface temperature associated with $\mathrm{SN}$ - shows a warming of the Mediterranean in July and the opposite with $\mathrm{SN}+$ in August, suggesting that temperature anomalies could be a precursor in the change of frequency of $\mathrm{SN}-$ and $\mathrm{SN}+$. 


\section{Introduction}

The North Atlantic/ Mediterranean region exhibits a great amount of atmospheric variability acting at different spatio-temporal scales with large nonlinearities in the system (Lamb and Peppler, 1987; Reusch et al., 2007; Cassou et al., 2004a). For example, a sizeable part of the Sea Level Pressure (SLP) variability is closely associated with that of large-scale teleconnection patterns, usually discriminated by tools based on a linear approach (Wallace and Gutzler, 1981). In particular, the North Atlantic Oscillation (NAO, Hurrell, 2003; Folland et al., 2009) which represents the largest percentage of SLP variability exhibits marked differences in opposite phases (Cassou et al., 2004a). Besides tropical/extratropical interactions do exist: the tropical convection can be responsible for North Atlantic variability, favoring occurrence and/or persistence of particular structures (Cassou, 2008; SanchezGomez et al., 2008), while the extratropical variability can impact on the more equatorial regions through Hadley-type circulation anomalies.

Sahelian rainfall variability, from intraseasonal to mutlidecadal timescale, is largely affected by variations of global and regional Sea Surface Temperature (SST) patterns (Folland et al., 1986; Giannini et al., 2003; Rowell, 2003). These SST variations include anomalies in the tropical Atlantic (Lamb, 1978, Vizy and Cook, 2001), the central and east Pacific (Janicot et al., 1996; Rowell, 2001), the Indian Ocean (Shinoda and Kawamura, 1994) and the Mediterranean Sea (Rowell et al., 1995; Rowell, 2003; Fontaine et al., 2009; Gaetani et al., 2010). Moreover, the stronger thermal contrast between the Sahara and surrounding favours a penetration of the mean circulation towards the African Sahel from the eastern tropicalequatorial Atlantic and the Mediterranean (Fontaine et al., 2003). According to Raicich et al. 
(2003), Fontaine et al. (2009) and Gaetani et al. (2010), warmer conditions over the Mediterranean (in JAS period) favour (i) a moderate weakening of the northeasterly flow east of $10^{\circ} \mathrm{E}$ and (ii) an enhancement of the northerly moisture flow from the eastern Mediterranean which reaches the eastern and central Sahel and increase the specific humidity.

Changes on rainfall over the Sahel region have been observed, like the contrast between the wet 50 's and 60 's and the dry 70 's and 80 's, or more recently the current rainfall recovery. The period from the late 70s exhibits also a change in the northern hemisphere teleconnection patterns (Johnson et al., 2008), which could be due to a warming trend in the tropical Sea Surface Temperatures (SST) (Hurrell et al., 2004). Werner et al. (2000) identified the decade 1981-1990 as the onset of climate change in the North Atlantic European sector with a trend starting in the beginning of the 70s. Several authors interpreted these changes in the variability patterns as a change in the intensity and frequency of Weather Regimes (Werner et al., 2000; Johnson et al., 2008), which, in turn, can be driven by changes in the Tropical SSTconvection (Cassou et al., 2004b; Hurrell, 2004; Cassou, 2008; SancheGomez et al., 2008).

A Weather Regime (WR) can be defined as a recurrent and persistent atmospheric state (Vautard, 1990, Michelangeli et al., 1995). The concept assumes that the atmosphere stays in discrete preferential states which are peaks in the probability density function of the phase space and are usually identified by cluster analysis (Vautard, 1990; Michelangeli et al., 1995; Plaut and Simonnet, 2001; Ghil and Robertson, 2002; Cassou et al., 2004a; Cassou, 2008; Moron et al., 2003; SanchezGomez et al., 2008). Moreover, the centroids of the nonlinear clustering methods can be seen as the corresponding "attractors" to the WR (Lorenz, 1963). In this way, low frequency variability can be interpreted as a change in the amplitude of these WR or in the preferred transitions between them (Robertson et al., 2000; Ghil and Robertson, 2002; Cassou et al., 2004a). 
Can such changes over the northern Atlantic/Mediterranean Sector be important in terms of climate impacts and in particular for the subtropical/tropical convection variability over West Africa (WA)? This question requires to define WRs from daily atmospheric data from May to October season and to project them onto rainfall information. The European Centre for Medium-Range Weather Forecast (ECMWF) reanalysis ERA-Interim has been chosen as the atmospheric information because it provides daily meteorological data at $1.5^{\circ}$ horizontal resolution on the period 1989-2008 and represents an improvement on certain key aspects of ERA40 such as the representation of the hydrological cycle (see Berrisford et al., 2009 for more details). Rainfall estimation is provided by the Global Precipitation Climatology Project (GPCP) for which 6,000 rain gauge stations, satellite geostationary, low-orbit infrared, passive microwave and sounding observations have been merged to estimate 5 days averaged rainfall on a 2.5-degree global grid from 1979 to the present (Gruber and Levizzani, 2008).

The aim of the present manuscript is twofold: (i) to present a collection from May to October WRs over a northern hemispheric region centered on the Mediterranean Sea (MS) from the illustrating and consistent Self Organizing Maps method and, (ii) to evaluate if the changes in frequency of these WRs are related to WA rainfall variability.

\section{The Method}

Self organizing maps (SOM, Kohonen, 2001) are based on artificial neural networks which allow the representation of high dimensional data space onto a reduced and ordered space. 
Therefore, it provides an alternative to other nonlinear cluster analysis techniques for defining WRs. Since a spatially organized set of patterns of variability of the data is obtained from SOM, it has been used in different fields with notable success. It has been recently used for oceanographic studies (Leloup al., 2007; Tozuka et al., 2008), for climate characterization over the northern hemisphere (Hewitson and Crane 2002; Reusch et al., 2007, Johnson and Feldstein, 2009) and also for rainfall prediction in the monsoon systems (Cavazos et al., 2002; Chattopadhyay et al., 2008) as well as for the study of the relationship between synoptic fields and heavy rainfall extreme events (Cavazos, 1999; Nishiyama et al., 2007). Several advantages of this methodology have been described, starting for being a powerful visualization approach (Reusch et al., 2007; Leloup et al., 2007). The patterns captured from the SOM present continuity in the data space due to the conservation of the topology of the structure in contrast with other clustering techniques, as agglomerative hierarchical algorithm (Mangiameli et al., 1996) or partitioning algorithm of $k$-means (Cassou et al., 2004a; Fereday et al., 2008) or partitioning algorithm of dynamic cluster method (Michelangelie et al., 1995). This continuity in the SOM structures provides an efficient way to easily identify the largescale atmospheric slow motions. These smoothly transitioning climate states of SOM array are indeed obtained from nonlinear classification of the continuum of atmospheric conditions. This continuum perspective is feasible with SOM and more realistic than commonly used discrete approach (Reusch et al., 2007; Johnson et al., 2008; Jonhson and Feldstein, 2009). In fact, Jonhson et al. (2008) and Jonhson and Feldstein (2009) showed that the Northern Hemisphere intraseasonal to interdecadal atmospheric variability can be understood in terms of changes in the frequency distribution of the cluster patterns that comprise this continuum.

Although works using SOM and other clustering methods as k-means for describing the winter North Atlantic variability have shown similar results (Cassou et al., 2004a; Reusch et 
al., 2007; Fereday et al., 2008), the SOM method reduces subjectivity which make it more attractive from usability point of view (Hewitson and Crane, 2002; Reusch et al., 2007). Since SOM assumes that the data are continuous, the method allows the representative patterns to span the phase space even when data are not highly clustered (Johnson et al., 2008). Mangiameli et al (1996) showed that the SOM is superior to hierarchical clustering methods in accuracy and robustness when applied in a synthetic set of data with different levels of imperfections. Therefore, SOM method strikingly distinguishes itself from other clustering methods through its topological ordering of the representative patterns.

For this study, an area centered over the MS $\left[60^{\circ} \mathrm{W}-60^{\circ} \mathrm{E} ; 15^{\circ} \mathrm{N}-70^{\circ} \mathrm{N}\right]$ has been chosen after checking that reducing/enlarging the size of this window does not modify the main WR features. 5x5 SOM-array of coupled SLP, geo-potential height and specific humidity at 700 $\mathrm{hPa}$ pressure level are used to identify 25 seasonal WRs occurring from May to October. Using three atmospheric variables gives us an accurate description of the WRs, although results do not substantially change when using the first two variables only (not shown). Before combining the three variables, each grid-point long-term anomalies have been normalized by their standard deviations to ensure that the three fields account for the same weight in the analysis. In addition, all data have been weighted by the cosine of latitude to take into account the dependence of the grid-point density on latitude. After verifying that results are not sensitive to the topology, we have chosen a hexagonal lattice structure of the array and a Gaussian neighborhood function. We have also tested the result's sensitivity to the size of the array. Ultimately, the choice of $5 \times 5$ SOM-array represents a good compromise between economy and the detail's resolution in the representative patterns, since the quantization error and border effects are reduced as the chosen number of SOM increases (Johnson et al., 2008). 
The algorithm presents the input data to a layer of neurons, which describe the positions on the two-dimensional grid that contains the representative patterns. The neurons have associated a weight or reference vector with the same dimension than the input data. The neurons are orderly disposed in a regular lattice and a global map shape is defined to evaluate how the neurons are connected, thus describing a topological map. Then a linear initialization is performed which implies that the weight vectors are initialized in an orderly fashion along the linear subspace spanned by the two leading eigenvectors of the covariance matrix of the training input data (this initialization have given better results than the random one for our data). Then an initial neighborhood function and initial learning rate are defined: several authors have showed that the choice of the learning rate and the initial neighborhood function radius does not change the results in a range of values (Mangiameli et al., 1996; Liu et al., 2006). We have used the so-called batch training algorithm to train the data in two phases. In this training algorithm two main processes take place: 1) The Best Matching Unit (BMU) is sought in each training step using the minimum Euclidean distance criterion between the neurons and the input data, 2) The weight vectors of the BMU and of its defined neighborhood are updated. The neighborhood function and the learning parameter are also updated and decrease at each time step. The first set of training iterations uses relatively large initial learning rate and neighborhood radius: this produces a first broad distribution of nodes. In the second phase, both learning rate and neighborhood radius are small from the beginning in order to refine the mapping (Mangiameli et al., 1996; Hewitson and Crane, 2002). The iterative phase is repeated until convergence of the parameters. More details are available in Vesanto et al., (2000) and at http://www.cis.hut.fi/projects/somtoolbox/. 
After determining the representative patterns, we classify each daily field to one of the SOM patterns using the criterion of minimum Euclidean distance; therefore each observation in the input data is associated with one and only one neuron via a weight vector. Later on, following the definition of WR, a criterion of persistence is imposed to keep only patterns that occur at least two consecutive days. The spatial correlation between the centroids (the $25 \mathrm{SOMs}$ ) and each corresponding patterns of the composite of daily data always shows a good agreement (from 0.9 spatial correlation scores). In this way, the final composites maps of theses recurrent and persistent structures are considered and hereafter referred to as WR (Figure 1).

\section{Results}

\section{a. Pattern Analysis}

Figure 1 shows the composite maps of anomalous SLP/Z700 with respect to the long-term May-October mean (Figure 2a), related to the SOM-array performed as described above. The mean months of the occurrence together with the frequency of occurrence over the season are displayed for each WR. Let us recall that four winter North Atlantic weather regimes have been described in the literature (Vautard, 1990; Moron et al., 2003; Cassou et al., 2004a; Ullmann and Moron, 2007; SanchezGomez et al., 2008, among others): (i) The Blocking regime with a strong anomalous high over Scandinavia; (ii) The Zonal regime (positive phase of the NAO) characterized by an enhanced zonal flow crossing the North Atlantic area due to a reinforced Island Low and Azores High; (iii) The Atlantic Ridge regime exhibiting a positive anomaly over the North Atlantic basin and low pressure over Northern Europe. Finally, (iv) the Greenland Anticyclone pattern (negative phase of the NAO) dominated by a strong positive anomaly centered over western Greenland. The NAO pattern is also found in 
summer season by empirical orthogonal function and cluster analyses. Summer NAO has a near-equivalent barotropic structure on daily and monthly time scales and is characterized by a more northerly location and smaller spatial scale than its winter counterpart (Fereday et al., 2008; Folland et al., 2009).

The SOM-based composites of daily SLP/Z700 shown in Figure 1 is in accordance with the patterns found in previous studies described above. These results exhibit mainly the seasonal cycle leading the highest variability of the variables (relative to the long-term mean in Figure 2a). Although the patterns are phase-locked with the seasonal cycle, it is also confirmed that the WR are the time-averaged signature of the quasi-daily atmospheric pattern variations (Cassou et al., 2004a). The negative NAO-like pattern (bottom-left WR 21) and the positive NAO-like pattern (top-right, WR 5) are well captured in spring and summer seasons respectively. A mid-North Atlantic pattern reflecting variability over Iceland low and the thermal Arabian low extends over Europe with opposite sign of these centers (top-left WR 1), and opposed in the SOM-array position and sign of the former WR 1, (bottom-right WR 25), frequent in early autumn and summer respectively. The remaining maps could be interpreted as intermediate patterns reflecting slow motions of the atmosphere state during transitions between the four main patterns, or simply belonging to one of these four main families of atmospheric circulation (see also the relative distances of the SOMs which are shown as a distortion surface according to Sammon (1969) in Figure 2b).

Frequency analysis illustrates how the seasonal variability is well captured (Figure 2c). The beginning of the season (from May to June) is characterized by high frequencies of WR 21 to 25 (bottom row in Figure 1). The sequence of WR 16 to 20 (the 4th row) is also associated with the spring season, although less frequent than WR 21 to 25 (Figure 2c). The seasonal 
peak (July-August) is defined mainly by WRs $20,15,10$ and $5\left(5^{\text {th }}\right.$ column in Figure 1$)$. In September-October, the decreasing in the WR number reports a sequence from summer to the beginning of autumn: from 5 to 1, $1^{\text {st }}$ row in Figure 1, but also albeit less frequent from 9 to 6 and from 14 to $11,2^{\text {nd }}$ and $3^{\text {rd }}$ rows respectively in Figure 1 . October is characterized by WR numbers $1,6,11$ and $16\left(1^{\text {st }}\right.$ column in Figure 1$)$. These above-mentioned sequences mainly represent the seasonal cycle with respect to the mean climatology (Figure 2a); the reinforcement of the Azores High and the Arabian-Sahara thermal low pressure systems from spring to summer and the enhancement of the Greenland Low pressure system from summer to autumn. However, although varying jointed in the seasonal cycle WR numbers describe also interannual variability, as referred later on by analyzing a particular interannual phenomenon.

Finally to complete the description of the seasonal cycle, figure $2 \mathrm{~d}$ presents the 2 first Principal Components (PC) of an Empirical Orthogonal Function applied on the WR occurrences (WR frequency along the season, therefore the size of the matrix is $25 \mathrm{x} \mathrm{184}$ ). It is found that the summer WR $\left(5^{\text {th }}\right.$ column in Figure 1$)$ are mostly associated with the PC1 (18\% of variance), while the PC2 (14\% of variance) describes mainly the WR occurring at the beginning (June) and at the end (September) of the season. This discrimination will be used later to examine the relationship between summer WR and WA rainfall.

Figure 3a presents the confidence level of the probability of the transition from $\mathrm{WR}_{\boldsymbol{i}}$ to $\mathrm{WR}_{\boldsymbol{j}}$. This has been calculated following Vautard et al. (1990), where the transition matrix can be reliable tested with a Monte Carlo test by assuming the representation of the large-scale atmosphere variability as a Markov chain of multiple flow regimes or WRs. A simple interpretation of Figure $3 \mathrm{a}$ would be that, along the $5 \times 5$ SOM-array in Figure 1, the flow 
diagram more likely of transitions occurs along the columns. For instance, WR $i$ given $i=10$, the most likely transition occurs towards WR 5, 15 or 20 , which corresponds to the same column in figure 1 or WR family. Also some groups of patterns belonging to the same row, such as $21-22-23 ; 3-4-5$ and $6-7-8$ are linked in the transitions. The largest probability is found in the persistence of each WR in remaining its own state (diagonal of the Transition matrix). This could be also measured as the mean persistence in days of each event and each WR. An event is defined as a sequence of days with the same characteristics lasting at least 2 days as in Vautard et al., (1990). Figure 3b displays the mean persistence of each WR together with the number of events counted for each WR. The WRs with the highest persistence are 1, $5,16,21,24$ and 25; the number of events is high for WRs 1, 5, 10, 11, 15, 20, 21 and 22 . Changes in the persistence of a particular WR could account for the probability of a phenomenon to occur such as more precipitation in a given area. This could be also interpreted as the consequence of an external forcing such as SST forcing (SanchezGomez et al., 2008). In the next section we investigate changes in the WR frequency associated with anomalous rainfall.

\section{b. Relationship with West African rainfall}

Are such changes in particular WR associated with the WA rainfall variability? In order to answer, we first classify years of positive and negative rainfall over the Sahel region. To this end, we perform a PC analysis for the anomalous rainfall along the year and the entire season averaged over the box $10^{\circ} \mathrm{W}-40^{\circ} \mathrm{W} ; 5^{\circ} \mathrm{N}-20^{\circ} \mathrm{N}$. From the leading $\mathrm{PC}$ index, positive and negative years of WA rainfall are classified and the differences of the mean frequency for each WR computed between these pools of years. Figure 4a shows the significant differences 
(at $p=0.10$ ) of the mean frequency for each WR regarding the wet and dry years. The most striking result is the more frequent occurrence at the beginning of the season of WR 17 and WR 21 in wet and dry years respectively and of WR 20 and WR 5 in July-August. These differences in mean frequency could be explained by changes in persistence of each WR and/or in its number of events. Thus in figure $4 \mathrm{~b}$ the number of events and persistence of WR 5 increases when years of negative anomalous rainfall occur over WA while WR 20 shows such an increase for years of positive WA rainfall anomalies. In contrast WR 21 presents a larger number of events but less persistence for dry years while WR 17 shows more number of events in wet years but no significant difference in persistence.

The significant differences detected in WR 5 and WR 20 occurs at the peak of the WA rainy season and exhibit similar frequency. This is the most intriguing feature for our purpose, since regarding wet and dry years, these WRs have opposite behavior in terms of persistence and number of events. Thus, in July-August, rainfall, SLP, Z700 and surface wind composites regarding WR 5 and WR 20 are first computed. Then the climatology is subtracted for considering only the WRs that do not match with the corresponding WR 5 and 20 for each map (Figure 5): this allows us to enhance the differences and to keep nonlinearities.

Figure 5 presents the differences between WR 5 and WR 20 occurrences. Figure 5a shows that WR 20 (WR 5) is related to more (less) Sahelian rainfall in July-August, which confirms our previous analyses. A zonally symmetric SLP/z700 pattern is also attested for both WRs (Figure 5b): WR 5 exhibits a summer positive NAO-like structure (hereafter WR 5 will be referred to as $\mathrm{SN}+$ ) with anomalous high pressures over Europe and anomalous low pressures over Greenland; WR 20 displays a summer negative NAO-like pattern (hereafter WR 20 will be referred to as $\mathrm{SN}-$ ) with positive anomalies over Island and negative ones over North 
Atlantic and the continent. The eastward displacement of the southern branch of the positive NAO-like pattern (centered over $20 \mathrm{~W}$ ) with respect to the negative phase (centered over 10E) is consistent with the winter and summer NAO phases (Cassou et al., 2004a; Folland et al., 2009). Surface winds associated with $\mathrm{SN}^{-}(\mathrm{SN}+)$ display anomalous northwesterlies (northeasterlies) related to lower (higher) pressures, and a subsequent inland (offshore) flow around $20^{\circ} \mathrm{N}$. This flow tends to enhance (to weaken) deep wet convection over $10 \mathrm{~W}-0 \mathrm{E}$ while in upper levels one notices an intensification (weakening) of the Tropical Easterly Jet and of the barotropic dipole structures in the extratropics (not shown). Additionally, the whole Mediterranean basin suffers a negative (positive) anomalous pressure.

$\mathrm{SN}-$ and $\mathrm{SN}+\mathrm{WR}$ behaviors in the month of maximum occurrence (i.e. July for SN- and August for $\mathrm{SN}+$ ) are illustrated in figure 5c. Basic SST patterns are discernable: an Atlantic Tripole-like pattern over the North Atlantic and warm SSTs over the MS for SN-; a cooler Subtropical North Atlantic and eastern MS for SN+. Such SST features in Eastern MS have been already discussed by other authors (Xoplaki et al., 2003; Fontaine et al., 2009) and related to interannual WA rainfall variability (Polo et al., 2008; Fontaine et al., 2009). Our results demonstrate that differences in SLP/Z700 fields associated with positive and negative anomalous rainfall over WA can be attributed to specific changes in the frequency distribution within the continuum of patterns. Moreover lead/lag analyses between SST fields and WR occurrences (not shown) reveal that MS SSTs could act as a precursor of these WRs and in turn explain part of their relationship with WA rainfall.

\section{Summary and Discussion}


This study provides evidence that Self Organizing Maps are a useful tool that provides a reliable and quasi-objective representation of Weather Regimes. This information can then be used in numerous diagnostic studies. The selected application concerns only their relationship with May-October West African rainfall. The results suggest that interannual rainfall anomalies over the Sahel are associated with changes in the frequency of occurrence of typical WRs. Thus, during abnormally wet (dry) years in WA, both higher frequencies of WR number 20 (5) and less frequent WR 5 (20) have been attested in July-August. This is associated with a zonal symmetric pattern, consistent along the middle troposphere, i.e., a low pressure anomaly centered over $50^{\circ} \mathrm{N}-20^{\circ} \mathrm{W}$ and Eurasia (Greenland) and a high pressure anomaly centered over Island (central Europe) for WR 20 (5) showing a SN- (SN+). Another striking characteristic of $\mathrm{SN}-(\mathrm{SN}+)$ is a southeastward (southwestward) surface anomalous winds flowing from (to) the Atlantic Ocean at $20^{\circ} \mathrm{N}$ and therefore able to enhance (weaken) wet convection.

This study shows that anomalous positive rainfall in the Sahelian region in JAS is associated with the SN- atmospheric pattern, highlighting the importance of the large-scale extratropical atmospheric circulation in the deep wet convection around $10 \mathrm{~W}-0 \mathrm{E}$ favouring Sahelian rainfall in JAS. A point of interest is that $\mathrm{SN}$ - is also associated with an anomalous warm Mediterranean that could feed the lower troposphere with additional moisture transported southwards northerlies and available for Sahelian rainfall (Fontaine et al., 2009; Gaetani et al., 2010). Moreover, lead/lag correlations have shown that an anomalous warm Mediterranean could be a precursor of higher frequency of daily WR 20 during July-September period. In order to confirm this hypothesis, we have performed preliminary analysis with Atmosphere General Circulation Models (AGCM) outputs forced by anomalous positive and negative SST anomalies over the MS and observed climatology elsewhere (Fontaine et al., 2009). Although this requires further analysis and is out of scope of this paper, the projection of the WR 
presented here onto the daily model outputs has shown that $\mathrm{SN}+\mathrm{WR}$ has higher (lower) frequency when considering the negative (positive) SST anomaly simulations. To summarize, this paper highlights the Mediterranean as a "key region" for Sahelian rainfall as a source of moisture as well as a possible precursor of the large-scale atmospheric circulation associated with anomalous positive rainfall anomalies in this region.

This study also implies further work in relation to WR. First of all, the utilities of the presented collection of WR include hence the projection onto model outputs. This work extension is being carried out by the authors through the AMMA project sensitivity experiment. Moreover, projection of WR on model outputs could also include AR4 and AR5 simulations in order to analyze changes in WR frequency. Then, still in the AMMA framework, an interesting work could be to analyze changes in frequency of WR (i.e. SN- and $\mathrm{SN}+$ ) around the onset period and the by end of the rainy season in order to better understand how large-scale atmospheric circulation and Mediterranean SST impact intraseasonal variability. Indeed, the presented WR can be used for a lot of other studies (i.e. heat wave in the Mediterranean). That's why we plan to make the collection of the daily WR available in the AMMA and HYMEX project databases. 


\section{Acknowledgments}

The authors would like to thank Thierry Castel for providing the ERA-Interim data. This research was supported by the European AMMA project from the $6^{\text {th }}$ Framework Research Programm and through a CNRS contract. The study was mainly supported by the Global change and Ecosystems programme EU Integrated project: African Monsoon Multidisciplinary Analysis (AMMA) and the French component of AMMA. Based on a French initiative, AMMA was built by an international scientific group and is currently funded by a large number of agencies, especially from France, UK, US and Africa. It has been the beneficiary of a major financial contribution from the European Community's Sixth Framework Research Programme. Detailed information on scientific coordination and funding is available on the AMMA International web site http://www.amma-international.org 


\section{References}

Berrisford, P., D. Dee, K. Fielding, M.Fuentes, P. Kallberg, S. Kobayashi and S. Uppala, 2009: The ERA-Interim archive. Version 1.0. ERA Report Series. (ECMWF).

Cassou C., J. W. Hurrell, and C. Deser, 2004a: North Atlantic winter climate regimes: Spatial asymmetry, stationarity with time, and oceanic forcing. J. Climate, 17, 1055-1068.

Cassou, C., C. Deser, L. Terray, J.W. Hurrell, and M. Drévillon, 2004b: Summer Sea Surface Temperature Conditions in the North Atlantic and Their Impact upon the Atmospheric Circulation in Early Winter. J. Climate, 17, 3349-3363.

Cassou, C., 2008: Intraseasonal interaction between the Madden-Julian Oscillation and the North Atlantic Oscillation. Nature, 455, 523-527.

Cavazos, T., 1999: Large-scale circulation anomalies conducive to extreme events and simulation of daily rainfall in northeastern Mexico and southeastern Texas. J. Climate, 12, $1506-1523$.

Cavazos, T., A. C. Comrie and A. M. Liverman, 2002: Intraseasonal Variability Associated with Wet Monsoons in Southeast Arizona.J. Climate, 15, 2477-2490.

Chattopadhyay, R., A. K. Sahai and B. N. Goswami, 2008: Objetive Identification of Nionlinear Convectively Coupled Phases of Monsoon Intraseasonal Oscillation: Implications for Prediction. J. Climate, 65, 1549-1569.

Fereday, D. R., J. R. Knight, A. A. Scaife and C. K. Folland, 2008: Cluster Analysis of North Atlantic-European Circulation Types and Links with Tropical Pacific Sea Surface Temperatures. J. Climate, 21, 3687-3703.

Folland, C. K., T. N. Palmer and D. E. Parker, 1986: Sahel rainfall and worldwide sea temperatures, 1901-85. Nature, 320, 602-607. 
Folland, C. K., J. Knight, H.W. Linderholdm, D. Fereday, S. Ineson and J. W. Hurrell, 2009: The Summer North Altantic Oscillation: Past, Present and Future. J. Climate, 22, 1082-1103. Fontaine, B., J. Garcia-Serrano, P. Roucou, B. Rodriguez-Fonseca, T. Losada, F. Chauvin, S. Gervois, S. Sijikumar, P. Ruti and S. Janicot, 2009: Impacts of warm and cold situations in the Mediterranean basins on the West African monsoon: observed connection patterns (19792006) and climate simulations, Clim. Dyn. DOI 10.1007/s00382-009-0599-3.

Fontaine B., P. Roucou and S. Trzaska, 2003: Atmospheric water cycle and moisture fluxes in the West African monsoon: mean annual cycles and relationship using NCEP/NCAR reanalyses, Geophys. Res. Lett., 30, 3, 10.1029-10.1032.

Gaetani M., B. Fontaine, P. Roucou and M. Baldi, 2010: Influence of the Mediterranean Sea on the West African Monsoon: intraseasonal variability in numerical simulations, accepted on 21 Sept, 2010 in Journal of Geophys. Research-Atmospheres.

Ghil, M. and A. W. Robertson, 2002: «Waves » vs «particles » in the atmosphere's phase space : A pathway to a long-range forecasting ?, PNAS, 99, 2493-2500.

Giannini, A., R. Saravanan and P. Chang, 2003: Oceanic Forcing of Sahel Rainfall on Interannual to Interdecadal Time Scales. Science, 302, 1027-1030.

Gruber, A. and V. Levizzani, 2008: Assessment of Global Precipitation Products. A project of the World Climate Research Programme Global Energy and Water Cycle Experiment (GEWEX) Radiation Panel. WCRP-128, WMO/TD-No. 1430.

Hewitson, B. C. and R. G. Crane, 2002: Self-organizing maps: applications to synoptic climatology. Climate Research, 22(1): 13-26.

Hurrell, J. W., 2003: An overview of the North Atlantic Oscillation.Geophys. Monogr. Series, 134, 1-22. Amer. Geophys. Union Eds.

Hurrell, J.W., M.P. Hoerling, A.S. Phillips, and T. Xu, 2004: Twentieth Century North Atlantic Climate Change. Part I: Assessing Determinism. Clim. Dyn., 23, 371-389. 
Janicot S., V. Moron and B. Fontaine, 1996: Sahel drought and ENSO dynamics. Geophys. Res. Lett, 23, 515-518.

Johnson, C. N., S. B. Feldstein and B. Tremblay, 2008: The continuum, of northern Hemisphere Teleconnection Patterns and a Description of the NAO Shift with the Use of SelfOrganizing Maps. J. Climate, 21, 6354-6371.

Johnson, N. C. and S. B. Feldstein, 2009: The Continuum of North Pacific Sea Level Pressure Patterns: Intraseasonal, Interannual and Interdecadal Variability. (submitted to J. Climate)

Kohonen, T., 2001: Self-Organizing Maps. Berlin, Germany, Springer-Verlag.

Lamb, P. J., and R. A. Peppler, 1987: North Atlantic Oscillation: Concept and application. Bull. Amer. Meteor. Soc., 68, 1218-1225.

Leloup, J. A., Z. Lachkar, J-P Boulanger and S. Thiria, 2007: Detecting decadal changes in ENSO using neural networks. Clim. Dyn., 28, 147-162.

Liu, Y., R. H. Weisberg, and C. N. K. Mooers, 2006: Performance evaluation of the selforganizing map for feature extraction.J. Geophys. Res., 111, C05018.

Lorenz, E. N., 1963: Deterministic nonperiodic flow. J. Atmos. Sci., 20, 130-148.

Mangiameli, P., S. K. Chen and D. West, 1996: A comparison of SOM neural network and hierarchical clustering methods. European J. of Operational Research, 93, 402-417.

Michelangeli, P., R. Vautard, and B. Legras, 1995: Weather regimes: Recurrence and quasi stationarity. J. Atmos. Sci., 52, 1237-1256.

Moron, V. and G. Plaut, 2003: The impact of El Niño southern oscillation upon weather regimes over Europe and the North Atlantic during boreal winter. Int. J. Climatology, 23, $363-379$.

Nishiyama, K., S. Endo, K. Jinno; C. B. Uvo, J. Olsson and R. Berndtsson, 2007: Identification of typical synoptic patterns causing heavy rainfall in the rainy season in Japan by a Self Organizing Map. Atm Res., 83, 185-200. 
Plaut, G. and E. Simmonet, 2001: Large-scale circulation classification, weather regimes, and local climate over France, the Alps and western Europe. Clim. Res., 17, 303- 324.

Polo, I., B. Rodríguez-Fonseca, T. Losada, and J. García-Serrano, 2008: Tropical Atlantic Variability Modes (1979-2002). Part I: Time-Evolving SST Modes Related to West African Rainfall. J. Climate, 21, 6457-6475.

Raicich F., N. Pinardi and A. Navarra, 2003: Teleconnections between Indian Monsoon and Sahel rainfall and the Mediterranean. Int. J. Climatol., 23, 173-186.

Reusch, D. B., R. B. Alley, and B. C. Hewitson, 2007: North Atlantic climate variability from a self-organizing map perspective. J. Geophys. Res., 112, D02104.

Robertson, A. W., C. Mechoso, and Y. Kim, 2000: The influence of Atlantic sea surface temperature anomalies on the North Atlantic Oscillation. J. Climate, 13, 122-138.

Rowell, D. P., 2003: The Impact of Mediterranean SSTs on the Sahelian Rainfall Season, J. Climate, 16, 849-862.

Rowell, D. P., C. K. Folland, K. Maskell and M. N. Ward, 1995: Variability of summer rainfall over tropical North Africa (1906-92): observations and modelling. Quart. J. Roy. Meteor. Soc., 121, 669-704.

Sammon, J. W., 1969: A nonlinear mapping for data structure analysis. IEEE Transactions on Computers C-18(5): 401-409.

SanchezGomez, E., C. Cassou, D. L. R. Hodson, N. Keenlyside, Y. Okumura and T. Zhou, 2008: North Atlantic weather regimes response to Indian-western Pacific Ocean warming: A multi-model study. Geophys. Res. Lett., 35, L15706.

Tozuka, T., J. J. Luo, S. Masson and T. Yamagata, 2008: Tropical Indian Ocean variability revealed by self-organizing maps. Clim. Dyn., 31, 333-343.

Ullmann, A. and V. Moron, 2007: Weather regimes and sea surge variations over the Gulf of Lions (French Mediterranean coast) during the $20^{\text {th }}$ century. Int. J. Climatology, 28: 159-171. 
Vautard, R., 1990: Multiple weather regimes over the North Atlantic: Analysis of precursors and successors. J. Climate., 118, 2056-2081.

Vautard, R., C. K. Mo and M. Ghil, 1990: Statistical Significance Test for Transition Matrices of Atmospheric Markov Chains. J. Atm. Sci, 47, 1926-1931.

Vesanto, J., J. Himberg, E. Alhoniemi and J. Parhankangas, 2000: SOM Toolbox for Matlab 5. ISBN: 951-22-4951-0, ISSN: 1456-2243. http:// www.cis.hut.fi/projects/somtoolbox.

Vizy E.K., and K.H. Cook, 2001: Mechanisms by which Gulf of Guinea and eastern NorthAtlantic sea surface temperature anomalies can influence African rainfall. J. Climate, 17, 795821.

Wallace, J. M. and D. Gutzler, 1981: Teleconnections in the géopotentiel fields during the Northern Hemisphere winter. Mon. Wea. Rev., 109, 784-812.

Werner, P. C., F. W. Gerstengarbe, K. Fraedrich and H. Oesterle, 2000: Recent Climate Change in the North Atlantic/European sector. Int. J. Climatol., 20, 463-471.

Xoplaki, E., J. F. Gonzalez-Rouco, J. Luterbacher and H. Wanner, 2003: Mediterranean summer air temperature variability and its connection to the large-scale atmospheric circulation and SSTs. Clim. Dyn., 20, 723-739. 


\section{List of Figures}

\section{Figure 1.}

May-June-July-August-September-October (MJJASO) Weather Regimes (composite anomalies with respect to the long-term seasonal mean represented in Figure 2a) of Sea Level Pressure (shaded areas $\mathrm{CI}=2 \mathrm{hPa}$ ) and geopotential height at $700 \mathrm{hPa}$ (contour lines $\mathrm{CI}=20 \mathrm{~m}$, zero line in grey) of 5x5 SOM-array analysis from Sea Level Pressure, geopotential height at $700 \mathrm{hPa}$ and specific humidity at $700 \mathrm{hPa}$ over the region and the period 1989-2008. The percentage at the top-right of each map gives the global population of a given WR. In parenthesis is given the months more likely of occurrence for each WR.

\section{Figure 2.}

a) Long-term Mean Sea Level Pressure (shaded areas in $\mathrm{hPa}$ ) and geopotential height at $700 \mathrm{hPa}$ (contour lines in $\mathrm{m}$ ) for the MJJASO season.

b) Sammon mapping of the SOMs computed and referred to Figure 1. It represents relative distance between the SOMs after the training. The reference of the four corners is given for a better visualization of the map's lattice.

c) Mean frequency of each WR along the season (days year ${ }^{-1}$ ).

d) Two first Principal Components of the WR occurrence along the season. The PCs describe the seasonal cycle corresponding to a pool of WR. The correlation coefficient scores between the two PCs and WR $5(\mathrm{SN}+)$ are $[0.74 ;-0.18]$ and between the two PCs and WR $20(\mathrm{SN}-)$ are $[0.78 ;-0.29]$. These two PCs represent $\sim 30 \%$ of variance. 


\section{Figure 3}

a) Confidence level of the probability of transition for each WR $(i)$ with the rest WR $(j)$. The transition matrix has been computed assuming the WRs behave as a Markov Chain and tested with a Monte Carlo test with 10000 permutations of the WR along the timeseries resting the number of events for each WR at $\mathrm{p}=0.10$.

b) Mean persistence (in days, blue line) and number of events (green line) of each WR.

\section{Figure 4}

a) Difference of the mean frequency occurrence for all the WRs between years of anomalous positive and negative rainfall over West Africa. Statistical significance has been tested with a Monte Carlo test with 10000 realizations at $\mathrm{p}=0.10$.

b) Difference of persistence (in days, blue line) and number of events (green line) for all the WRs between years of anomalous positive and negative rainfall over West Africa.

\section{Figure 5}

a) Composite anomalies of rainfall (in $\mathrm{mm} \mathrm{day}^{-1}$ ) of occurrence of WR 20 (SN-, top panel) and WR 5 ( $\mathrm{SN}+$, bottom panel) in July and August minus the mean of July and August without considering the WR selected.

b) Same as a) but for SLP (shaded areas, in $\mathrm{hPa}$ ), $\mathrm{Z} 700$ (contour lines, $\mathrm{CI}=20 \mathrm{~m}$, zero line in grey) and surface winds (vectors, in $\mathrm{m} \mathrm{s}^{-1}$ ).

c) Same as a) but for the SST (in K) and the subtraction of the climatology is done for July and August for SN- and SN+ respectively. 

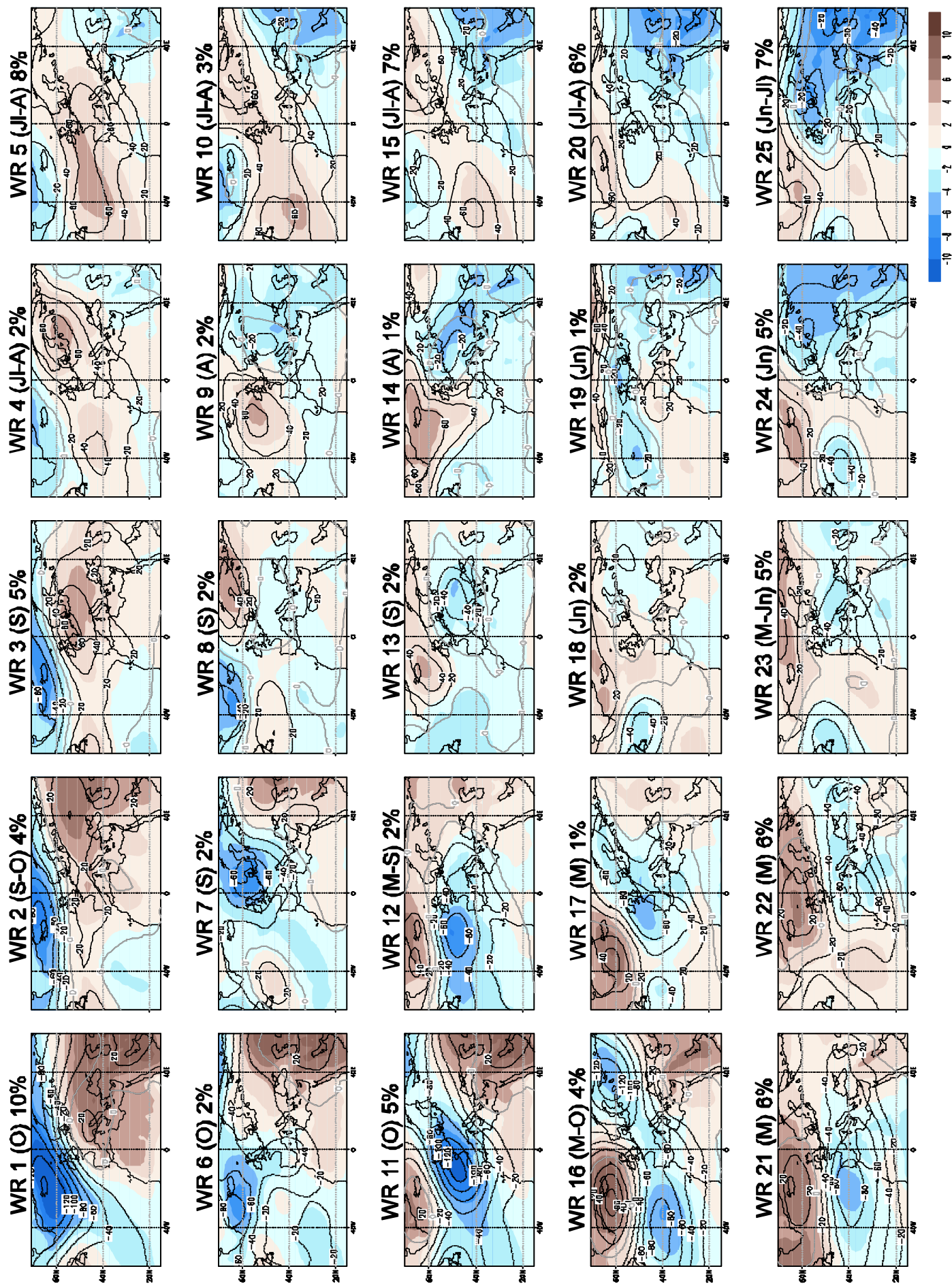

Figure 1. May-June-July-August-September-October (MJJASO) Weather Regimes (composite anomalies with respect to the long-term seasonal mean represented in Figure 2a) of Sea Level Pressure (shaded areas $\mathrm{CI}=2 \mathrm{hPa}$ ) and geopotential height at $700 \mathrm{hPa}$ (contour lines $\mathrm{CI}=20 \mathrm{~m}$, zero line in grey) of $5 \times 5 \mathrm{SOM}$-array analysis from Sea Level Pressure, geopotential height at $700 \mathrm{hPa}$ and specific humidity at $700 \mathrm{hPa}$ over the region and the period 1989-2008. The percentage at the top-right of each map gives the global population of a given WR. In parenthesis is given the months more likely of occurrence for each WR. 

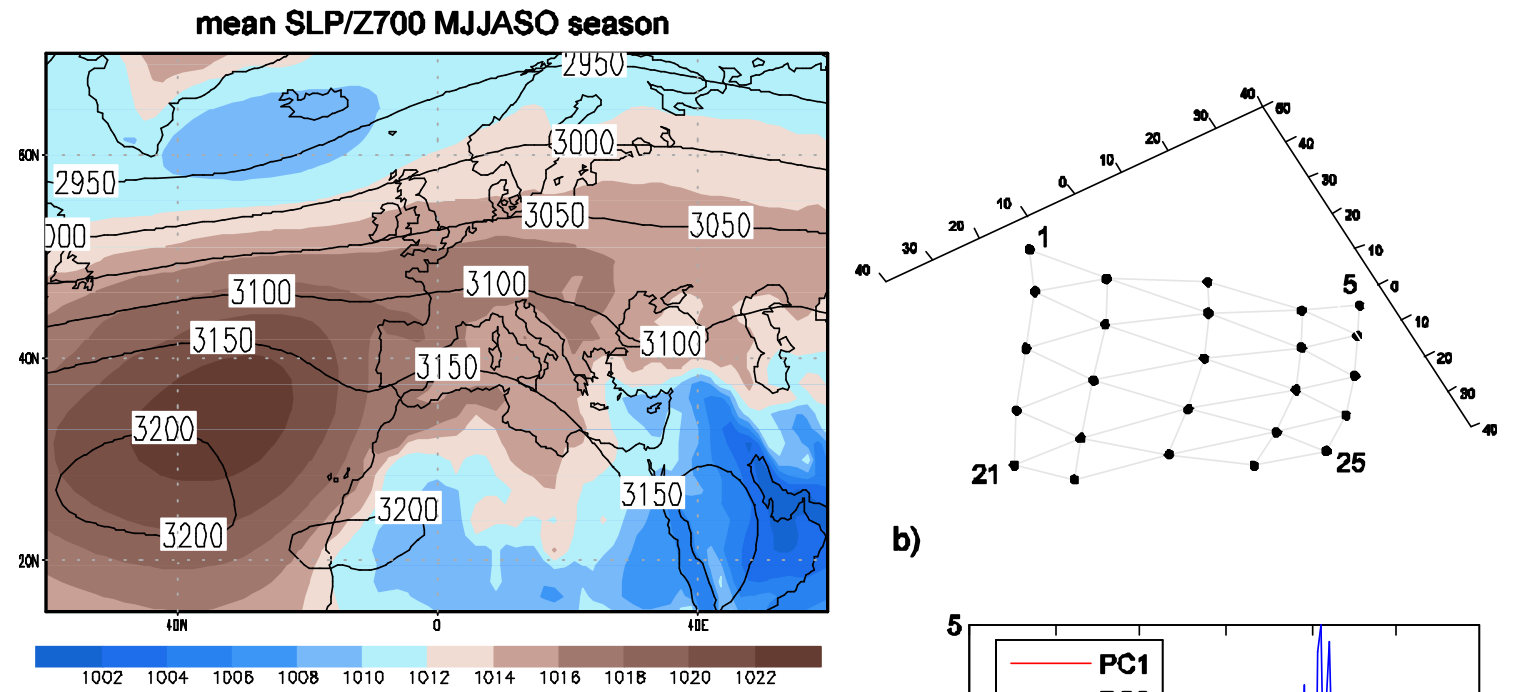

b)

a)
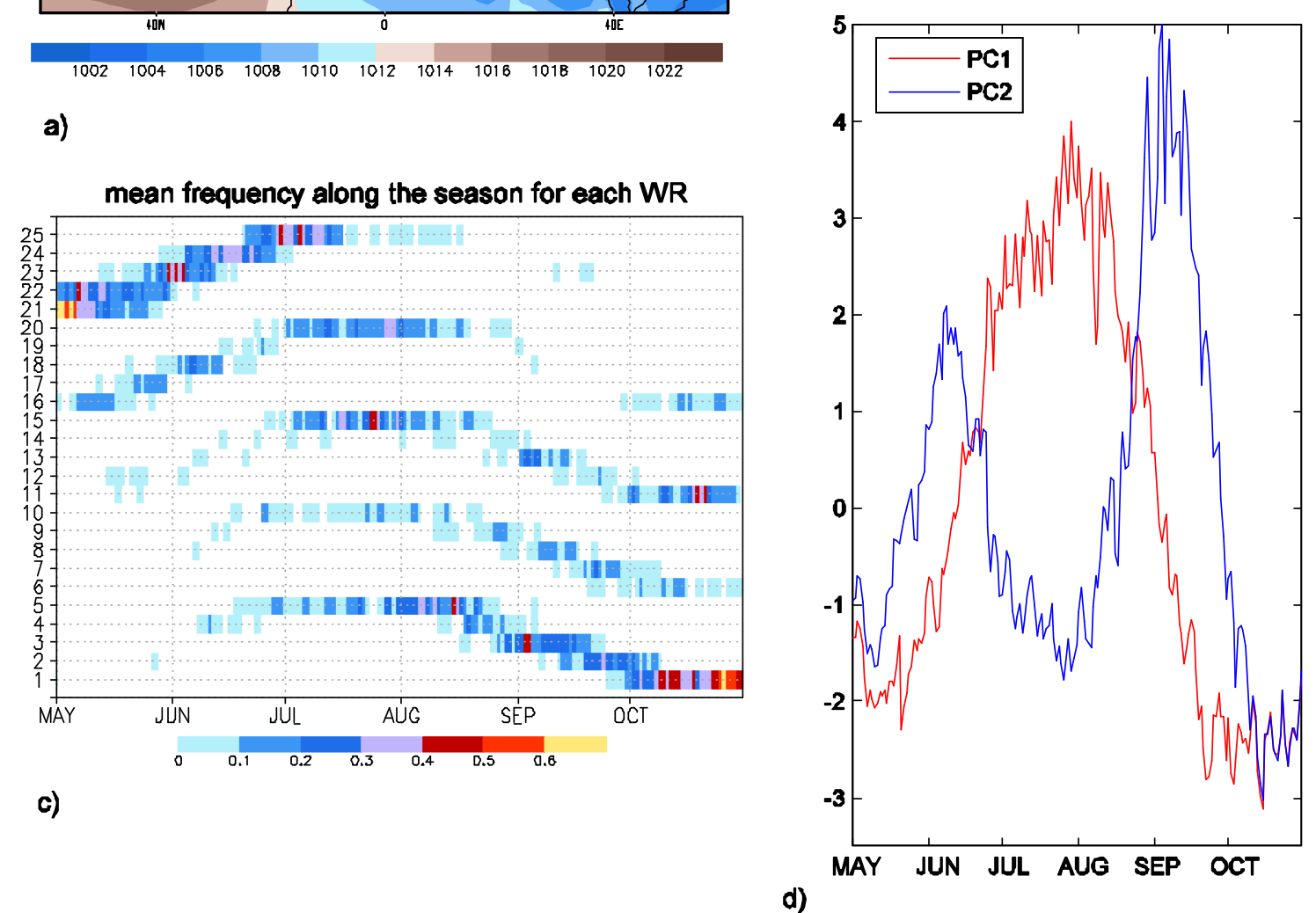

Figure 2.

a) Long-term Mean Sea Level Pressure (shaded areas in $\mathrm{hPa}$ ) and geopotential height at $700 \mathrm{hPa}$ (contour lines in m) for the MJJASO season.

b) Sammon mapping of the SOMs computed and referred to Figure 1. It represents relative distance between the SOMs after the training. The reference of the four corners is given for a better visualization of the map's lattice.

c) Mean frequency of each WR along the season (days year ${ }^{-1}$ ).

d) Two first Principal Components of the WR occurrence along the season. The PCs describe the seasonal cycle corresponding to a pool of WR. The correlation coefficient scores between the two PCs and WR $5(\mathrm{SN}+)$ are $[0.74 ;-0.18]$ and between the two PCs and WR 20 (SN-) are $[0.78 ;-0.29]$. These two PCs represent $\sim 30 \%$ of variance. 

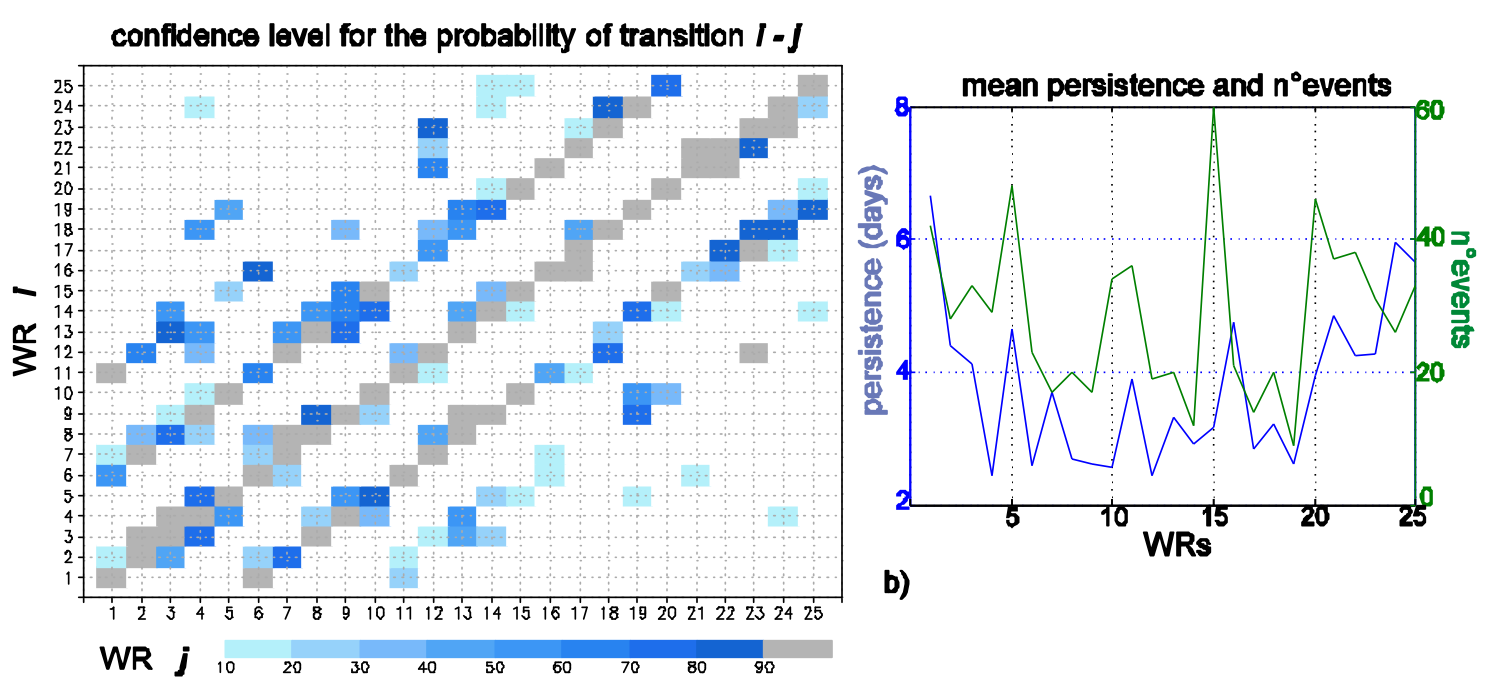

b)

a)

\section{Figure 3.}

a) Confidence level of the probability of transition for each WR $(i)$ with the rest WR $(j)$. The transition matrix has been computed assuming the WRs behave as a Markov Chain and tested with a Monte Carlo test with 10000 permutations of the WR along the timeseries resting the number of events for each WR at $\mathrm{p}=0.10$.

b) Mean persistence (in days, blue line) and number of events (green line) of each WR. 
difference of mean frequency WAM $+/-C L=90 \%$
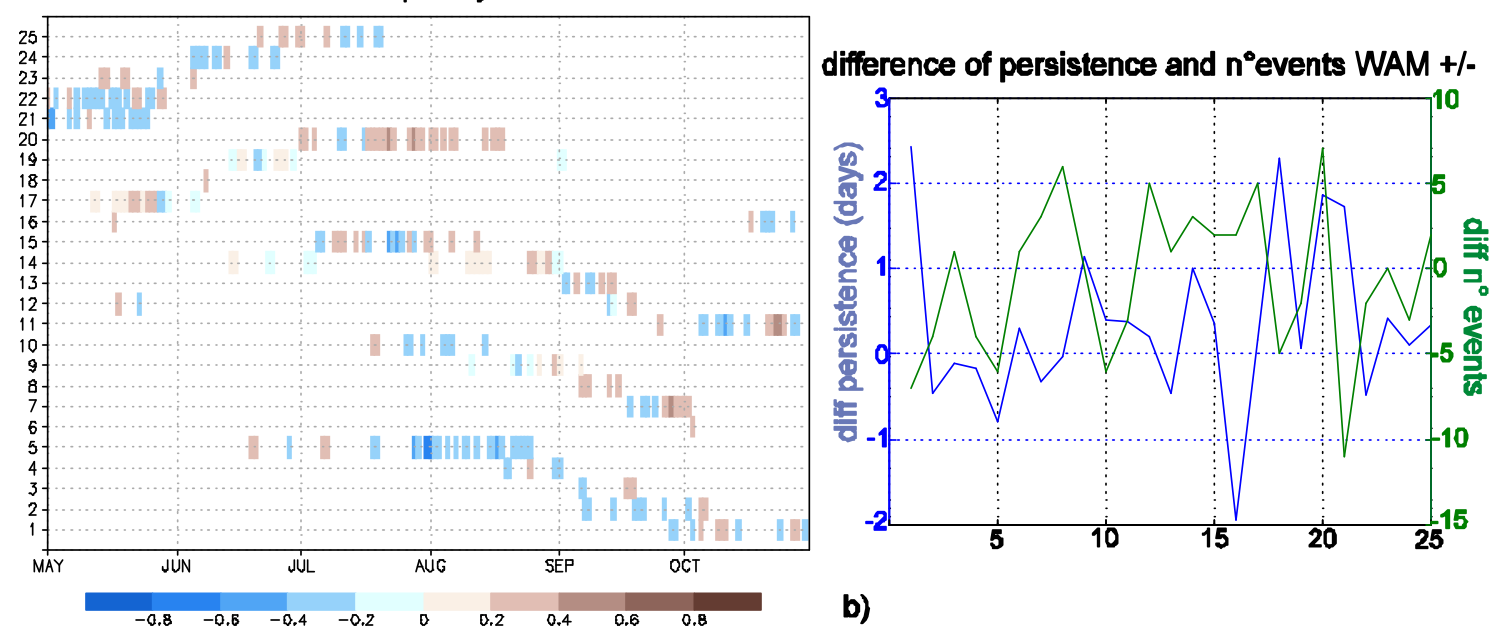

a)

Figure 4 .

a) Difference of the mean frequency occurrence for all the WRs between years of anomalous positive and negative rainfall over West Africa. Statistical significance has been tested with a Monte Carlo test with 10000 realizations at $\mathrm{p}=0.10$.

b) Difference of persistence (in days, blue line) and number of events (green line) for all the WRs between years of anomalous positive and negative rainfall over West Africa. 

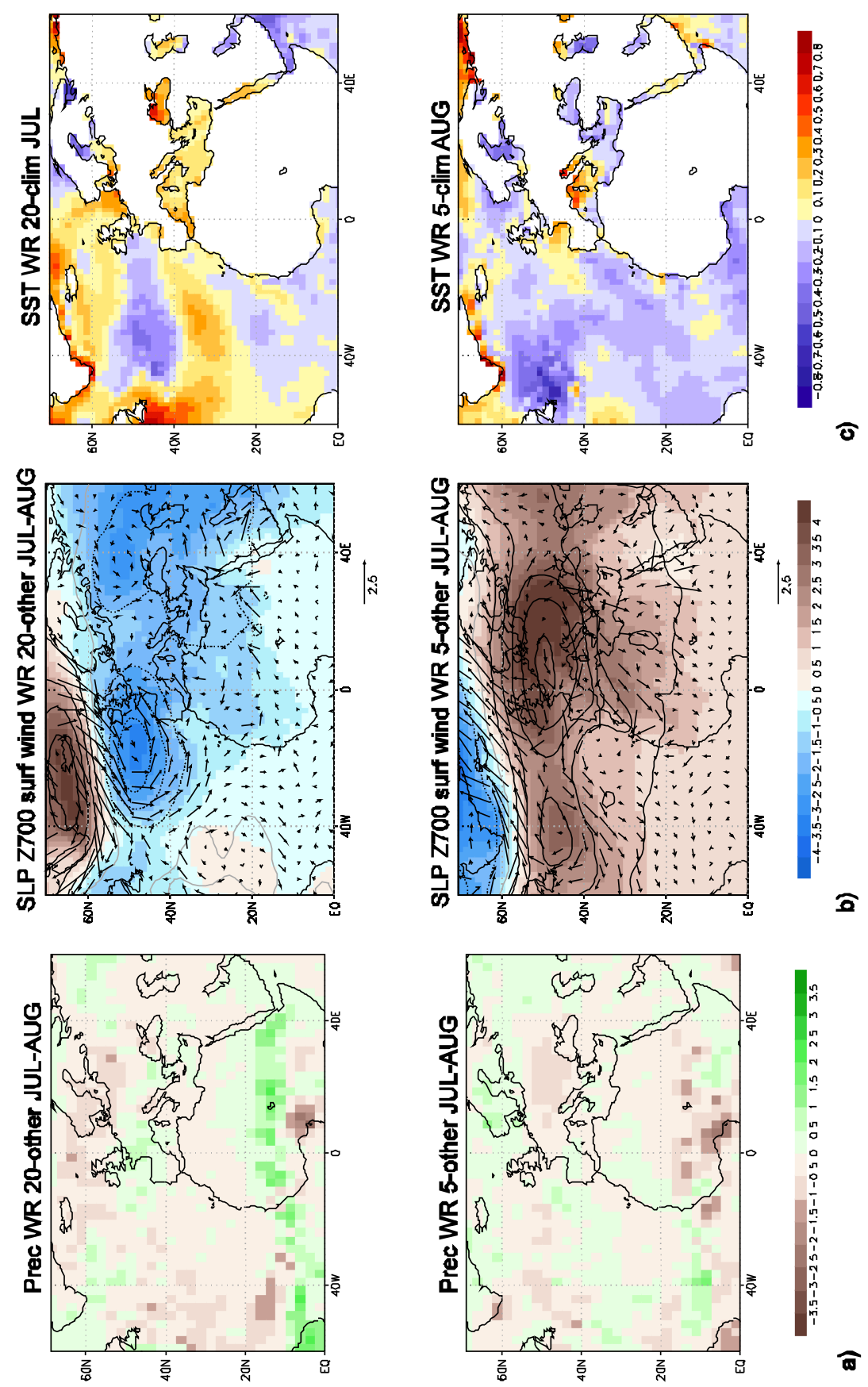

Figure 5.

a) Composite anomalies of rainfall (in $\mathrm{mm} \mathrm{day}^{-1}$ ) of occurrence of WR 20 (SN-, top panel) and WR 5 (SN+, bottom panel) in July and August minus the mean of July and August without considering the WR selected.

b) Same as a) but for SLP (shaded areas, in $\mathrm{hPa}$ ), Z700 (contour lines, CI=20 m, zero line in grey) and surface winds (vectors, in $\mathrm{m} \mathrm{s}^{-1}$ ).

c) Same as a) but for the SST (in K) and the subtraction of the climatology is done for July and August for SNand $\mathrm{SN}+$ respectively. 